\title{
Cultivation of Important Methanotrophs From Indian Rice Fields
}

\author{
Monali C. Rahalkar ${ }^{1,2 * t}$, Kumal Khatri ${ }^{1,2+}$, Pranitha Panditt,2, Rahul A. Bahulikar ${ }^{3}$ and \\ Jyoti A. Mohite ${ }^{1,2}$
}

' C2, Bioenergy Group, MACS Agharkar Research Institute, Pune, India, ${ }^{2}$ Department of Microbiology, Savitribai Phule Pune University, Pune, India, ${ }^{3}$ Central Research Station, BAIF Development Research Foundation, Pune, India

OPEN ACCESS

Edited by:

Nagamani Balagurusamy, Universidad Autónoma de Coahuila, Mexico

Reviewed by:

Sanjay Kumar Singh Patel, Konkuk University, South Korea Muhammad Farhan UI Haque, University of the Punjab, Pakistan

Karthikeyan Subburamu, Tamil Nadu Agricultural University,

India

*Correspondence:

Monali C. Rahalkar

monalirahalkar@aripune.org

${ }^{t}$ These authors have contributed equally to this work and share first authorship

Specialty section: This article was submitted to Microbiotechnology, a section of the journal Frontiers in Microbiology

Received: 18 February 2021

Accepted: 09 August 2021 Published: 03 September 2021

Citation:

Rahalkar MC, Khatri K, Pandit $P$, Bahulikar RA and Mohite JA (2021) Cultivation of Important Methanotrophs From Indian Rice Fields. Front. Microbiol. 12:669244. doi: 10.3389/fmicb.2021.669244
Methanotrophs are aerobic to micro-aerophilic bacteria, which oxidize and utilize methane, the second most important greenhouse gas. The community structure of the methanotrophs in rice fields worldwide has been studied mainly using cultureindependent methods. Very few studies have focused on culturing methanotrophs from rice fields. We developed a unique method for the cultivation of methanotrophs from rice field samples. Here, we used a modified dilute nitrate mineral salts (dNMS) medium, with two cycles of dilution till extinction series cultivation with prolonged incubation time, and used agarose in the solid medium. The cultivation approach resulted in the isolation of methanotrophs from seven genera from the three major groups: Type la (Methylomonas, Methylomicrobium, and Methylocucumis), Type lb (Methylocaldum and Methylomagnum), and Type II (Methylocystis and Methylosinus). Growth was obtained till $10^{-6}-10^{-8}$ dilutions in the first dilution series, indicating the culturing of dominant methanotrophs. Our study was supported by 165 rRNA gene-based next-generation sequencing (NGS) of three of the rice samples. Our analyses and comparison with the global scenario suggested that the cultured members represented the major detected taxa. Strain RS1, representing a putative novel species of Methylomicrobium, was cultured; and the draft genome sequence was obtained. Genome analysis indicated that RS1 represented a new putative Methylomicrobium species. Methylomicrobium has been detected globally in rice fields as a dominant genus, although no Methylomicrobium strains have been isolated from rice fields worldwide. Ours is one of the first extensive studies on cultured methanotrophs from Indian rice fields focusing on the tropical region, and a unique method was developed. A total of 29 strains were obtained, which could be used as models for studying methane mitigation from rice fields and for environmental and biotechnological applications.

Keywords: methane, novel, India, rice fields, cultivation, metagenomics, methanotrophs, serial dilution

\section{INTRODUCTION}

Methane is the second most important greenhouse gas after carbon dioxide. Aerobic methanotrophs use methane gas as their sole source of carbon and energy source (Hanson and Hanson, 1996). Most of the described and available methanotrophs belong to the phylum Proteobacteria. Methanotrophs belonging to the phylum Verrucomicrobia (Pol et al., 2007) and 
Candidatus phylum NC-10 have also been described in recent years (Ettwig et al., 2010; Dedysh and Knief, 2018). The proteobacterial methanotrophs are classified as Type I (Gammaproteobacteria) and Type II (Alphaproteobacteria) based on the internal cell structure, phylogeny, and carbon assimilation pathway. Methanotrophs inhabit rice fields (Frenzel, 2012), lakes (Pester et al., 2004; Rahalkar, 2007; Oswald et al., 2016), wetlands (Dedysh, 2009), soda lakes (Antony et al., 2012), compost (Kim et al., 2008), forest soils (Dunfield et al., 2003), peat bogs (Pytlak et al., 2012), thermal springs (Hirayama et al., 2011), and marine sediments (Bowman et al., 1997; Tavormina et al., 2015).

The scholarly work of Whittenbury et al. (1970) started a new era of cultured methanotrophs in 1970. In the last 50 years, several new genera and species have been documented, and a large proportion of the diversity of aerobic methanotrophs has been brought into culture. However, several lineages lack cultivated representatives and pose challenges for further cultivation studies (Dedysh and Dunfield, 2014; Dedysh and Knief, 2018). Cultivation of indigenous methanotrophs is crucial, and studies targeting their metabolism, physiology, and biochemistry would help understand them in detail (Bowman, 2011). Methanotrophs can also produce industrially important biomolecules and can be used to produce methanol by using methane as a feedstock (Patel et al., 2018b, 2019, 2020a,b). Biomolecules such as single-cell protein, biopolymers, methanol, formaldehyde, organic acids, ectoine, lipids (biodiesel and health supplements), growth media, and vitamin B12 (Oremland and Culbertson, 1992; Al Hasin et al., 2010; Strong et al., 2015; Patel et al., 2018b) can be produced using methanotrophs using methane.

Rice fields form an important niche for aerobic methanotrophs, where they oxidize about $20 \%$ of the methane produced (Conrad, 2009). Both Type I (gammaproteobacterial) and Type II (alphaproteobacterial) methanotrophs are present in the rice rhizosphere (Qiu et al., 2008; Shrestha et al., 2008; Reim et al., 2012; Shiau et al., 2018). Culture-independent analysis of rice field samples showed the following methanotrophs to be present: Methylobacter, Methylomicrobium, and Methylomonas (Type Ia); Methylocaldum, Methylococcus, and uncultured (Type Ib); and Methylocystis (Type II) (Noll et al., 2008; Lüke et al., 2010; Ma et al., 2013). However, very few members have been cultured, and several $p m o A$ lineages, rice paddy cluster (e.g., RPC1-3), detected remain uncultured (Lüke, 2010; Knief, 2015). Only a handful of cultivation-based studies worldwide have targeted the cultivation of methanotrophs from rice fields (Dianou et al., 2009; Ferrando and Tarlera, 2009; Pandit et al., 2016; Frindte et al., 2017). In each of documented studies, members of up to four genera have been cultured.

Here, we report extensive efforts taken to culture dominantly present methanotrophs from Indian rice fields. We describe here a method that could be used for the enrichment and isolation of methanotrophs from a rice field sample. We used a mineral medium that had been successfully used before for culturing rice field methanotrophs. A first set of dilution till extinction was set up and incubated for a prolonged time for $6-8$ weeks. In a second dilution series using microtiter plates, we could achieve isolation of single methanotroph cultures, which were then further purified as pure or axenic cultures by plating on a solid medium and restreaking. This way, the slow-growing but numerically dominant cultures were given a chance to grow; and many pure cultures were obtained as a result. Additionally, we used 16S rRNA genebased next-generation sequencing (NGS) to document the actual diversity of methanotrophs present in a few samples.

\section{MATERIAL AND EQUIPMENT}

\section{Growth Media}

(1) Nitrate mineral salts (NMS) medium (Whittenbury et al., 1970) g/L: $\mathrm{MgSO}_{4} 7 \mathrm{H}_{2} \mathrm{O}, 1 ; \mathrm{CaCl}_{2} 2 \mathrm{H}_{2} \mathrm{O}, 0.2 ; \mathrm{KNO}_{3}, 1 ; \mathrm{SL} 10$ solution, $1 \mathrm{ml} ; \mathrm{Fe}_{3} \mathrm{NH}_{4}$ Citrate solution, $1 \mathrm{ml}$.

Post autoclave additions: phosphate buffer ( $\mathrm{pH} 6.8$ ), $20 \mathrm{ml} / \mathrm{L}$ and vitamin solution $(1 \times), 10 \mathrm{ml} / \mathrm{L}$.

(2) Modified dilute NMS (dNMS) medium (Pandit et al., 2016) g/L: $\mathrm{MgSO}_{4} 7 \mathrm{H}_{2} \mathrm{O}, 1 ; \mathrm{CaCl}_{2} 2 \mathrm{H}_{2} \mathrm{O}, 0.2 ; \mathrm{KNO}_{3}, 0.25 ; \mathrm{SL} 10$ solution, $1 \mathrm{ml} ; \mathrm{Fe}_{3} \mathrm{NH}_{4}$ citrate solution, $1 \mathrm{ml}$; HEPES buffer (2 M, pH 7), $1 \mathrm{ml}$.

Post autoclave additions: phosphate buffer ( $\mathrm{pH} 6.8$ ), $2 \mathrm{ml} / \mathrm{L}$, and vitamin solution $(1 \times), 10 \mathrm{ml} / \mathrm{L}$.

(3) Solidifying agent: $2 \%$ agarose.

(4) Stock solution compositions are as follows:

(a) SL10 (trace element solution) mg/L: $\mathrm{ZnCl}_{2}, 70 ; \mathrm{MnCl}_{2} 2 \mathrm{H}_{2} \mathrm{O}$, 100; $\mathrm{Na}_{2} \mathrm{MoO}_{4} 2 \mathrm{H}_{2} \mathrm{O}, 36 ; \mathrm{CuCl}_{2} 2 \mathrm{H}_{2} \mathrm{O}, 17 ;{ }^{*} \mathrm{FeCl}_{4} 4 \mathrm{H}_{2} \mathrm{O}, 1,500$; $\mathrm{CoCl}_{2} 6 \mathrm{H}_{2} \mathrm{O}, 190 ; \mathrm{H}_{3} \mathrm{BO}_{3}, 62 ; \mathrm{NiCl}_{2} 6 \mathrm{H}_{2} \mathrm{O}, 24 ;{ }^{*} \mathrm{HCl}(25 \%)$, $10 \mathrm{ml}$. Note: Prepare $25 \% \mathrm{HCl}$ and dissolve $0.15 \mathrm{~g} / 1,500 \mathrm{mg}$ of $\mathrm{FeCl}_{4} 4 \mathrm{H}_{2} \mathrm{O}$ in $1 \mathrm{ml}$ of $25 \% \mathrm{HCl}$.

(b) $\mathrm{Fe}_{3} \mathrm{NH}_{4}$ citrate: $0.2 \mathrm{~g} / 50 \mathrm{ml}$ of distilled water.

(c) Phosphate buffer, pH 6.8 (g/L): $\mathrm{Na}_{2} \mathrm{HPO}_{4}, 3.6$, and $\mathrm{KH}_{2} \mathrm{PO}_{4}$, $1.4 \mathrm{~g} / \mathrm{L}$ addition. Autoclaved phosphate buffer stock solution was stored at $4-8^{\circ} \mathrm{C}$ (refrigeration).

(d) Vitamin solution $(1 \times)$ : chemicals dissolved as mg/L: biotin, 2; folic acid, 2; pyridoxine- $\mathrm{HCl}, 10$; thiamine- $\mathrm{HCl} 2 \mathrm{H}_{2} \mathrm{O}, 5$; riboflavin, 5; nicotinic acid, 5; D-Ca-pantothenate, 5; vitamin B12, 20; $p$-aminobenzoic acid, 5; lipoic acid, 5; nicotinamide, 5; pyridoxal $\mathrm{HCl}, 5$; and L-ascorbic acid, $5 \mathrm{mg}$ per liter.

Phosphate buffer and vitamin stock solutions were sterilized separately.

All the chemicals or reagents were of analytical grade of the brands Sisco Research Laboratories Pvt. Ltd. (SRL) or Sigma Aldrich Chemicals Private Limited.

\section{Cultivation Material}

(1) Serum bottles-65- or 35-ml capacity.

(2) Silicone butyl rubber stoppers, aluminum crimp seals, and a bottle crimper.

(3) Glass desiccators of 25-L volume.

\section{Microscopy}

(1) Phase-contrast microscope, Nikon 80i, Japan microscope with 10,40 , and $100 \times$ (oil emersion lens) objective lenses.

(2) Scanning electron microscopy (SEM) (Zeiss model EVO-MA15 SEM).

(3) Slides for phase-contrast microscopy and glass coverslips. 


\section{DNA Extraction}

(1) Bacterial DNA extraction-Sigma GenElute ${ }^{\mathrm{TM}}$ Bacterial Genomic DNA Kit (Gram-negative protocol).

(2) Soil DNA extraction-MP Biomedicals FastDNA ${ }^{\mathrm{TM}}$ Spin Kit for Soil DNA Extraction.

\section{Methane Oxidation Measure}

Chemito 8510 Gas Chromatograph, India, equipped with a flame ionization detector (FID). Conditions: column PorapakQ (80/100 mesh size, $3.2 \mathrm{~mm} \times 2 \mathrm{~mm})$; injector temperature $110^{\circ} \mathrm{C}$; detector temperature $120^{\circ} \mathrm{C}$; oven temperature $100^{\circ} \mathrm{C}$; flow rates of carrier gasses, nitrogen (15-18 $\mathrm{ml} / \mathrm{min})$, hydrogen $(50 \mathrm{ml} / \mathrm{min})$, and air $(250 \mathrm{ml} / \mathrm{min})$.

\section{Molecular Identification}

\section{(1) $\quad p m o A$ gene primers:} GGNGACTGGGACTTCTGG-3')

189 and

(5'-CGGNGCAACGTCYTTACC-3').

(2) Universal 16S rRNA primers: 27 forward (5'AGAGTTTGATCMTGGCTCAG-3') and 1492 reverse (5'-TACGGYTACCTTGTTACGACTT-3').

\section{METHODS}

\section{Step 1: Sampling}

Rice field samples were collected from three geographical locations from Kerala and Maharashtra states in India (Supplementary Table 1). Most of the samples were collected at the end of the monsoon in October. The plants were in the late flowering to grain-bearing stage this month. Due to difficulties in the accessibility of the region in Kerala, where there are heavy rains in the monsoon season, we collected samples from the Kerala rice fields and marshy area in December. Three of the samples (KRF, KM, and KB) were used for the culture-independent analysis of methanotrophs using 16S rRNA gene-based NGS targeting the V3-V4 region. Cultivation of methanotrophs was done from all five locations (Supplementary Table 1). The sampling was done as described before (Pandit et al., 2016), where pooled soil samples from three to five distantly located rice plants from each rice field were used. The rice plants were uprooted with the entire root system and the attached soil. Only rhizospheric soil was collected by removing the bulk soil and scraping the soil attached to the roots. In one case, soil attached to the stem (1-3 cm from the roots) was collected. The samples from Kerala were collected in sterile sealed gas-tight bags and brought to the lab in the shortest possible time (3-4 days). All the samples were immediately transported to the laboratory on the same day and were processed as detailed earlier (Pandit et al., 2016). The samples were immediately used for enrichment experiments, some portion was stored at $-20^{\circ} \mathrm{C}$ for DNA extraction, and the remaining samples were stored at $4-8^{\circ} \mathrm{C}$ for further experimentation.

\section{Step 2: Enrichment and Isolation}

The entire procedure for the enrichment and isolation of methanotrophs is shown in a flow chart (Figure 1).

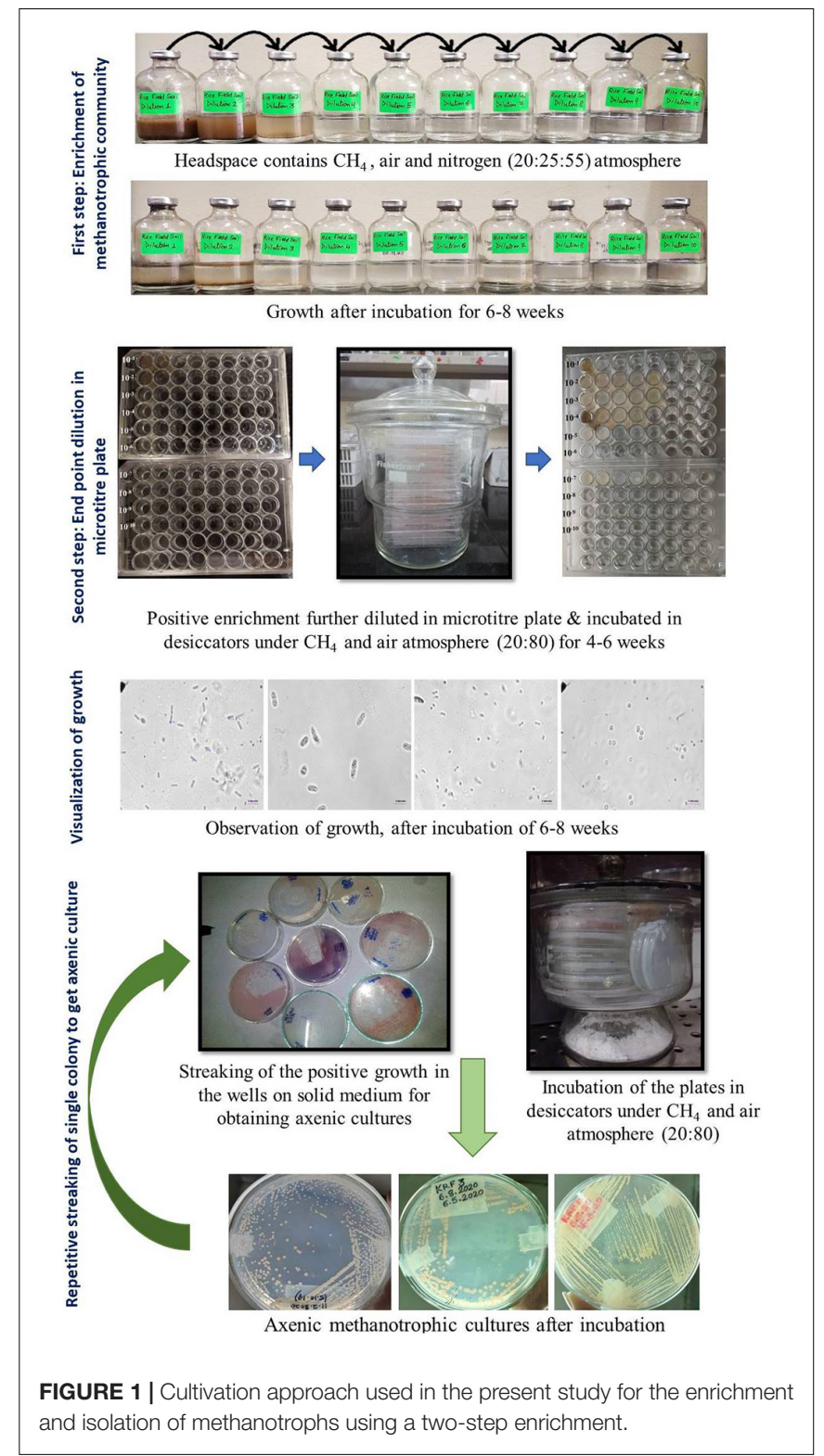

\section{Enrichment of Methanotrophic Community}

1. The modified dNMS medium was prepared as described previously (Pandit et al., 2016). The salts $\left(\mathrm{MgSO}_{4} \cdot 7 \mathrm{H}_{2} \mathrm{O}\right.$, $\mathrm{KNO}_{3}$, and $\mathrm{CaCl}_{2}$ ) were dissolved in distilled water as per given in Growth Media, part 2.

2. The medium was boiled to remove dissolved oxygen and cooled under nitrogen gas flushing conditions under a gassing manifold.

3. After being cooled, SL-10 trace element solution, $0.4 \%$ $(\mathrm{w} / \mathrm{v})$ ferric ammonium citrate solution, and $2 \mathrm{M}$ of HEPES buffer (pH 6.8) were added.

4. The $\mathrm{pH}$ was adjusted to 6.8 using $5 \mathrm{M}$ of $\mathrm{NaOH}$ or $\mathrm{KOH}$.

5. Serum bottles (65-ml volume) were filled with $18 \mathrm{ml}$ of sterile dilute (dNMS) medium (Pandit et al., 2016), and headspace was flushed with nitrogen gas and autoclaved. 
6. After being cooled, phosphate buffer and vitamins were added.

7. The samples were serially diluted from $10^{-1}$ to $10^{-10}$ by adding $2 \mathrm{ml}$ or $2 \mathrm{~g}$ of sample to an $18 \mathrm{ml}$ sterile (dNMS) medium (Growth Media, part 2).

8. A headspace volume of $45 \%$ was removed with a sterile syringe and filled with $20 \%$ methane and $25 \%$ air. All the gasses were added using a syringe and a needle through a sterile filter $(0.2 \mu \mathrm{m})$.

9. The bottles were incubated under static conditions and $25^{\circ} \mathrm{C}$ in the dark.

10. Methane oxidation was checked periodically using Chemito 8510 Gas Chromatography (Mumbai, India), equipped with a FID.

11. The bottles were incubated for $\sim 6-8$ weeks, and the gas phase was replaced after every 10 days with the same gas mixture as described above.

12. Growth was recorded in the form of turbidity, flakes, or pellets. A simultaneous decline in methane accompanied by growth in the form of visual turbidity, pellicle, or biofilm at the bottom was considered an indication of methanotrophic growth and considered a positive enrichment.

\section{End-Point Dilution in Microtiter Plate}

Positive methanotroph enrichment of $100 \mu \mathrm{l}$ was diluted in sterile $900 \mu \mathrm{l}$ of dNMS media added to a 48 -well microtiter plate, and dilution up to $10^{-8}$ was done. The microtiter plates were placed in a glass airtight desiccator under methane:air environment (20:80) and incubated at $25^{\circ} \mathrm{C}$ for $4-8$ weeks.

\section{Visualization of Growth}

1. Wet mounts were observed under a phase-contrast microscope Nikon 80i (Tokyo, Japan) microscope under 1, 40 , and $100 \times$ (oil emersion lens) objective lenses.

2. Cells growing in the enriched liquid in microtiter plates were observed.

3. After growth in the wells was visualized, 50-100 $\mu$ l of the liquid was streaked onto $2 \%$ agarose dNMS solid media plates and incubated in desiccators under methane:air environment $(20: 80)$ and incubated at $25^{\circ} \mathrm{C}$ for $4-6$ weeks.

4. The desiccators were opened and checked for growth after every week (Figure 1).

\section{Repetitive Streaking of Single Colony to Get Axenic Culture}

1. Each isolated colony growing on the agarose medium, which was incubated in the presence of methane, was picked up using sterile toothpicks or wire loops. The cells from every unique colony were observed and re-streaked for purification.

2. Wet mounts from all single colonies appearing on plates incubated under methane were visualized under a phasecontrast microscope (Nikon) equipped with a computer, and images were taken.

3. After several rounds of re-streaking, pure methanotrophic isolates were obtained.

\section{Purity Check}

The purity of each methanotroph was checked by streaking it on a heterotrophic medium (dilute nutrient agar plus $0.1 \%$ glucose or a complete nutrient agar plate). No growth on either of these media was taken as an indication of the purity of the methanotroph.

\section{Step 3: Morphological Characterization}

The morphological characteristics such as colony color, colony morphology, and liquid growth characteristics (pellicle, turbidity, or biofilm) were recorded. Each culture was grown in liquid dNMS medium in 65-ml-capacity serum bottles with $20 \%$ methane in the headspace. The decline in methane was followed over time. Each pure culture was grown and processed to observe under a SEM (Zeiss, Oberkochen, Germany; model EVO-MA-15 SEM). Sample preparation for SEM has been described before (Pandit et al., 2018). Analysis of methane oxidation potential of representative strains of each genus was carried out, and the corresponding growth in terms of optical density (OD) was measured for a period of 15 days (Supplementary Material).

\section{Step 4: DNA Extraction, PCR Amplification, and Sequencing}

1. After it was confirmed that the cultures oxidized methane and were pure, DNA extraction was done using either liquid culture pellets or colonies picked from a freshly growing plate. DNA extraction from the isolates was done as described before (Pandit et al., 2016).

2. Particulate methane monooxygenase $\beta$ subunit ( $p m o A$ ) gene amplification and $16 \mathrm{~S}$ rRNA gene amplification were carried out using A189f-mb661r primers and 27f and 1492r primers as described before (Pandit et al., 2016) using the extracted DNA from pure cultures.

3. The amplified products were sequenced using initially one and then with forward and reverse primers; and First Base Laboratories, Malaysia, did the sequencing.

4. The sequences obtained using both the primers were aligned and assembled using SeqMan (DNASTAR, Lasergene software) and were subjected to BLAST analysis [sequences of all of the unique isolates were deposited in the National Center for Biotechnology Information (NCBI) database]. If the similarity between the isolates was more than $99.5 \%$, only a single sequence was submitted. Each strain of the methanotroph was classified based on its colony characters, blast using $16 \mathrm{~S}$ rRNA gene, and $p m o A$ partial sequence and assigned to the genus and possible species level.

\section{Step 5: Whole-Genome Sequencing and Analysis}

The whole-genome analysis was carried out as described before (Khatri et al., 2021). The whole-genome sequencing of the culture RS1 was outsourced and done using the Illumina HiSeq platform (151*2) at MedGenome Labs, Bangalore, India. De novo assembly of the sequenced reads was done by using SPADES De novo Assembler (v3.13.0). The contig files were submitted 
to RAST $^{1}$, and submitted to the NCBI including the NCBI prokaryotic genome annotation pipeline $\mathrm{PGAP}^{2}$. The genome of strain RS1 compared with genomes of its closest members was done to calculate the average nucleotide identity (ANIb$\left.\mathrm{G}^{3}\right)$, digital DNA-DNA hybridization $\left(\mathrm{dDDH}^{4}\right)$, and the average amino acid identity $\left(\mathrm{AAI}^{5}\right)$.

\section{Step 6: 16S rRNA Next-Generation Sequencing Targeting the V3-V4 Region}

1. Metagenomic DNA from the soil samples (KB, KM, and KRF) was extracted using the FAST DNA spin kit for soil (MP Biomedicals, Irvine, CA, United States).

2. After the initial quality was checked using NanoDrop and run on an agarose gel, further $16 \mathrm{~S}$ rRNA NGS targeting the V3-V4 region was done by Sandor Lifesciences Pvt. Ltd. (Hyderabad, India) (KB and KM samples) and in Helical Lab, Pune (KRF samples).

3. The DNA was amplified using primers specific to the V3V4 hypervariable region of the 16S rRNA gene.

4. The library was sequenced on an Illumina HiSeq/MiSeq PE 150 , i.e., $150 \times 2$, using paired-end sequencing.

5. Other procedures were done as per the standard operating conditions of each vendor. The companies also performed adaptor trimming, and the read sequence reads specific to the families Methylococcaceae and Methylocystaceae were extracted using Perl script and given to us.

6. Additionally, the data were also checked for the presence of Methylocella and Methylacidiphilum. These extracted reads from the families Methylococcaceae and Methylocystaceae were used for the phylogenetic tree constructions.

7. The extracted fas files for each family or genus were blasted in NCBI using nucleotide blast, and the data for abundance for each methanotrophic genus was collected. A cutoff of 95\% (16S rDNA fragment) was used for classifying a particular sequence in that genus. The genus and species data were used to calculate the bar diagram ratios for Methylococcaceae and Methylocystaceae.

${ }^{1}$ http://rast.nmpdr.org/

${ }^{2}$ https://www.ncbi.nlm.nih.gov/genome/annotation_prok/

${ }^{3} \mathrm{http} / / /$ jspecies.ribohost.com/jspeciesws/\#analyse

${ }^{4}$ http://ggdc.dsmz.de/

${ }^{5} \mathrm{http}: / /$ enve-omics.ce.gatech.edu/aai/

\section{Step 7: Phylogenetic Analysis}

1. The $16 \mathrm{~S}$ rRNA sequences from high-throughput sequencing were aligned using $\mathrm{MAFFT}^{6}$ and the reference sequences extracted from $\mathrm{NCBI}^{7}$.

2. The partial sequences $16 \mathrm{~S}$ rRNA gene sequences obtained in the NGS were used for the tree construction using the maximum-likelihood bootstrap analysis using other sequences from Methylococcaceae members. Evolutionary analyses were conducted in MEGA7 (Kumar et al., 2016).

3. Similarly, a tree with Methylocystaceae sequences (total of 104 sequences) with average 173 nucleotides in length were used for the construction of a phylogenetic tree using MEGA X (Kumar et al., 2018).

4. A common tree using the $16 \mathrm{~S}$ rRNA gene sequences of the representative isolates obtained in this study was constructed using maximum-likelihood analysis with 1,000 bootstraps compared with the closely associated members. The phylogenetic trees were constructed using MEGA X and analyzed based on the Tamura-Nei model.

5. The phylogenetic analysis of the putative novel isolate RS1 was done using both the 16S rRNA gene and the partial $p m o A$ gene using maximum-likelihood analysis with 1,000 bootstraps compared with the closely associated methanotrophs. The phylogenetic trees were constructed using MEGA $\mathrm{X}$ and analyzed based on the TamuraNei model.

\section{RESULTS}

\section{Isolation and Cultivation of Methanotrophs From Seven Genera Using Currently Developed Method}

A two-step dilution till extinction enrichment process was used for the cultivation of methanotrophs, where we used serum bottles for the first step followed by serial dilution of each of the positive enrichment in microtiter plates in eight steps (Figure 1). The first enrichment was carried out for 6-8 weeks. Growth was accompanied by methane oxidation, and it was in the form of

\footnotetext{
${ }^{6}$ https://mafft.cbrc.jp/alignment/server/

${ }^{7}$ https://www.ncbi.nlm.nih.gov/
}

TABLE 1 | Cultivated methanotroph strains from various samples*

\begin{tabular}{|c|c|c|c|c|}
\hline Serial number & Methanotrophs genus & Species/putative novel & $\begin{array}{l}\text { Total number of isolates, (novel) } \\
\text { isolation source }\end{array}$ & $\begin{array}{l}\text { Dilution (serum bottle) from which the } \\
\text { cultures were isolated }\end{array}$ \\
\hline (1) & Methylomonas & koyamae, denitrificans, methanica & 12(1), KRF, Kb, Kerala mud & $10^{-2}-10^{-5}$ \\
\hline (2) & Methylomicrobium & Novel species & 2 (1), Mulshi & $10^{-5}$ \\
\hline (3) & Methylocucumis & oryzae & 1 (Mulshi) & $10^{-5}$ \\
\hline (4) & Methylomagnum & ishizawai & $1, \mathrm{KRF}$ & $10^{-4}$ \\
\hline (5) & Methylocaldum & gracile & 1, Mulshi & $10^{-7}$ \\
\hline
\end{tabular}

*Total strains from each genus are shown, and the number of putative novel species is indicated in brackets followed by sample number. Taxa from which novel strains were isolated are marked in bold. 
pellicle, biofilm, or turbidity and was seen up to $10^{-1}$ to $10^{-8}$ dilutions in the samples (Table 1). The second dilutions series showed cultures with single morphotypes in the highest dilutions. In most cases, plating the highest dilution from the second series resulted in a mono-culture of a methanotroph after plating. On average, three to four streaking steps resulted in the pure cultures. A total of 29 strains of methanotrophs were cultured in pure form (Table 1). The primary dilution of the sample is indicated for the isolates. Most of the isolates were obtained from the highest dilutions reflecting their dominance in the environment (Table 1). Cells showed large and characteristic cells with coccoid, elliptical, fat, or long rod morphology and mostly showed internal granules. All the cultures exhibited methanotrophy, i.e., grew with methane as the sole source of carbon and energy. All the cultures oxidized methane after an initial lag phase and consumed half in a 5-7 days' interval and showed a simultaneous growth with an increase in the OD. The growth curves of representative strains showed a maximum increase in the OD of 0.15-0.2 with simultaneous methane oxidation (Supplementary Material). The isolated strains belonged to seven genera after NCBI blast analysis of the $16 \mathrm{~S}$ rRNA and partial pmoA genes (Table 1).

\section{Isolation of Methylomonas, Methylosinus, Methylocystis, Methylomicrobium, Methylomagnum, Methylocaldum, and Methylocucumis Strains}

The strains belonged to the following genera: Methylomonas, Methylomicrobium, Methylocaldum, Methylomagnum, Methylocucumis (Methylococcaceae), and Methylocystis and Methylosinus (Methylocystaceae) (Table 1 and Supplementary Table 2). Seventeen strains belonging to Methylococcaceae were isolated, and 12 strains belonged to Methylocystaceae. The highest number of strains was from the Methylomonas genus (12 strains) followed by the genus Methylosinus (eight strains), genus Methylocystis (four strains), Methylomicrobium (two strains), Methylomagnum (one strain), Methylocucumis (one strain), and Methylocaldum (one strain). Methylomonas, Methylocystis, and Methylosinus were isolated from the majority of samples. The phylogenetic tree (Figure 2) shows that the isolates fall into all the three important clades of proteobacterial methanotrophs. The Methylomonas strains majorly showed pink to orangecolored colonies. Methylomagnum strain KRF4 represented a new member of Methylomagnum ishizawai (Frindte et al., 2017), the first report from India. A Methylocaldum gracile strain, KAR5Ro7, was isolated from the Mulshi sample. Methylocucumis oryzae strain BM10 represented a new strain of the genus and species $M$. oryzae, thereby being the second strain of this genus and species, which was initially a single species and single strain genus (Pandit and Rahalkar, 2018; Pandit et al., 2018). Thus, Type Ia methanotrophs representatives of Methylomonas, Methylomicrobium, and Methylocucumis; Type Ib Methylomagnum and Methylocaldum; and Type II Methylocystis and Methylosinus strains were cultured, covering the three major groups.

\section{$16 S$ rRNA Gene-Based Next-Generation Sequencing of Three of the Rice Samples}

The methanotrophic community structure in three rice rhizospheric soils was elucidated using the V3-V4 amplicon NGS in KB and KM samples from the Pune and Konkan regions and KRF sample from the Kerala region to analyze the microbial diversity. The bar diagram (Figure 3 and Table 2) shows the distribution of the sequences.

In two of the three samples, $\mathrm{KB}$ and $\mathrm{KM}$, a dominance of Methylococcaceae (Type I methanotrophs) was found over Methylocystaceae sequences (Type II methanotrophs). The ratio of Methylococcaceae:Methylocystaceae was $\sim 2.3$ in cases (Table 2). A geographic distance of $117 \mathrm{~km}$ separates both these fields. The diversity of Methylococcaceae-related sequences was abundant in both locations, where at least five to six genera were detected within the family Methylococcaceae. Among the abundant genera, the Type Ib group consisting of Methylolobus sp., Methylococcus sp., Methylocaldum sp., and Methylomagnum sp. (25.6\% and $33.9 \%$ ) occupied the major abundance in KB and KM samples. Within the Methylococcaceae, members of at least six to seven different genera were detected in each sample (Figure 3). Additionally, the sequences related to Type Ia methanotrophs, Methylomicrobium (11.8 and 3.7\%), Methylobacter marinus/Methylomarinum (9.7 and $1.8 \%$ ), and Methylomonas (6.1 and 7.4\%) were found in dominance. A minority percentage of 1.5 and $3.7 \%$ were occupied by the species Methylobacter tundripaludum or Methylosoma difficile in samples $\mathrm{KB}$ and $\mathrm{KM}$, respectively. In the KM sample, Methylolobus sequences dominated and were in equal numbers, and the Methylocystis-related sequences were present. Within the family Methylocystaceae (Type II), the genera's abundance varied in $\mathrm{KB}$ and $\mathrm{KM}$ samples. Genus Methylosinus was abundant in the $\mathrm{KB}$ sample with $18.5 \%$ followed by $11.8 \%$ of genus Methylocystis. In the KM sample, the genus Methylocystis was abundant with $16.5 \%$, and genus Methylosinus occupied $12.8 \%$ of the abundance. The third field, KRF, from Kerala, showed a higher number of Methylocystaceae sequences (87\%), and the ratio of Methylococcaceae to Methylocystaceae was 0.15 (Table 2). The raw data obtained from the 16S rRNA gene-based NGS of the rice samples have been deposited as PRJNA505747. The phylogenetic tree of the clones from this study belonging to the Type I methanotrophs (Methylococcaceae family) showed major clades close to the genera Methylomicrobium, Methylocaldum, and Methylolobus (Supplementary Figure 1). The phylogenetic analysis of the Type II methanotrophs showed affiliation to Methylocystis and Methylosinus species (Supplementary Figure 2).

\section{A Putative New Species of Methylomicrobium Strain RS1}

A strain RS1 was isolated from a rice stem sample (soil attached to the stem just above the surface), which showed $~ 98 \%$ 16S rRNA gene similarity (MH764455.1, 1,363-bp sequence) with the 16S rRNA gene of Methylomicrobium album ATCC $35068^{\mathrm{T}}$. The partial pmoA sequence ( $\sim 500 \mathrm{bp}$ ) showed $93.9 \%$ 


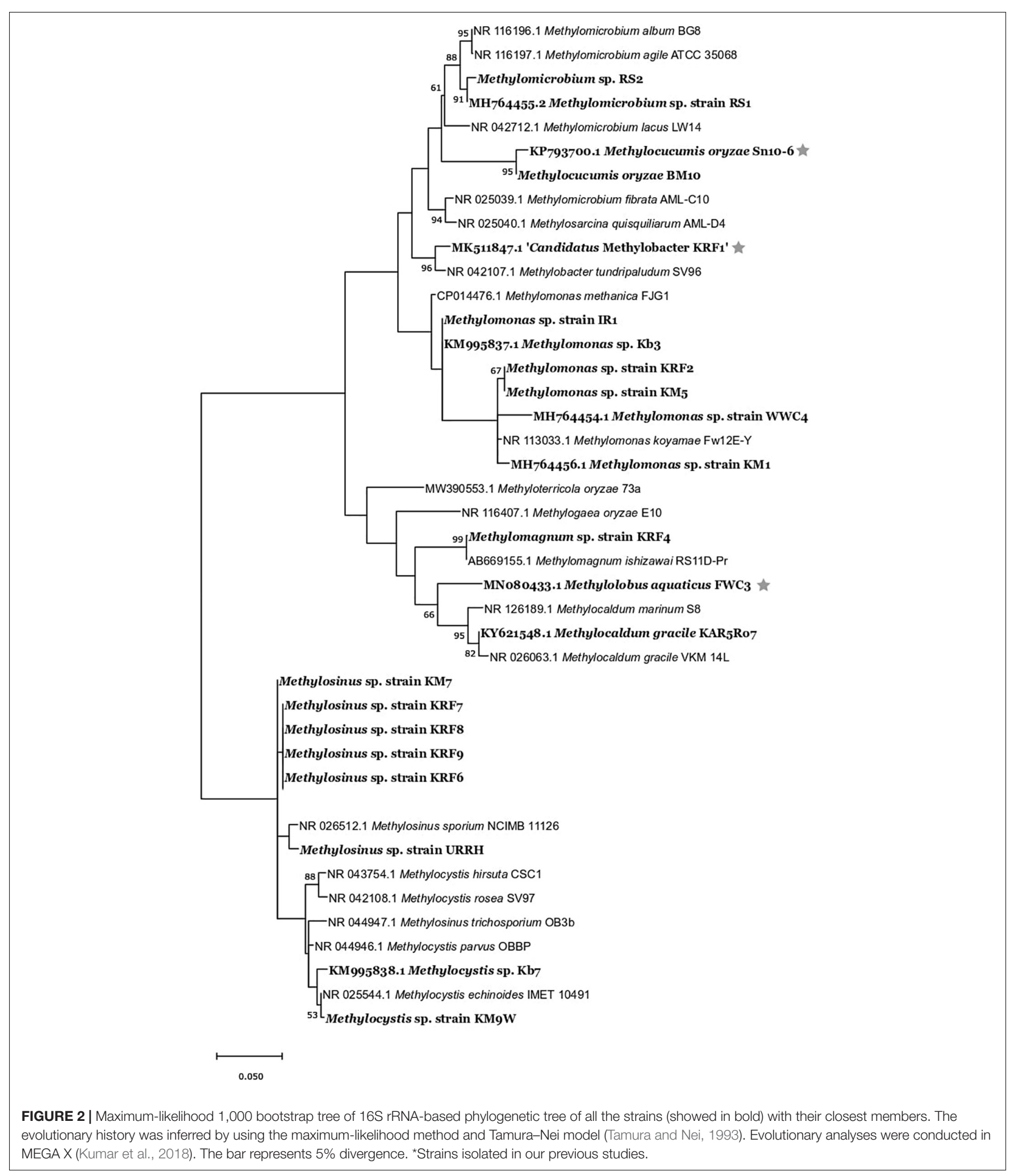

pmoA similarity with the $p m o A$ gene of the same organism, M. album ATCC $35068^{\mathrm{T}}$. The colonies of RS1 were white to cream in color, and the cells show a fat rod-elliptical cell type of morphology (Supplementary Figure 3). Another strain, RS2, virtually identical and showing $99.9 \%$ similarity in the $16 \mathrm{~S}$ rRNA gene, was also isolated from the seven enriched strains. We further analyzed only RS1 in detail; both of them were nearly identical. 


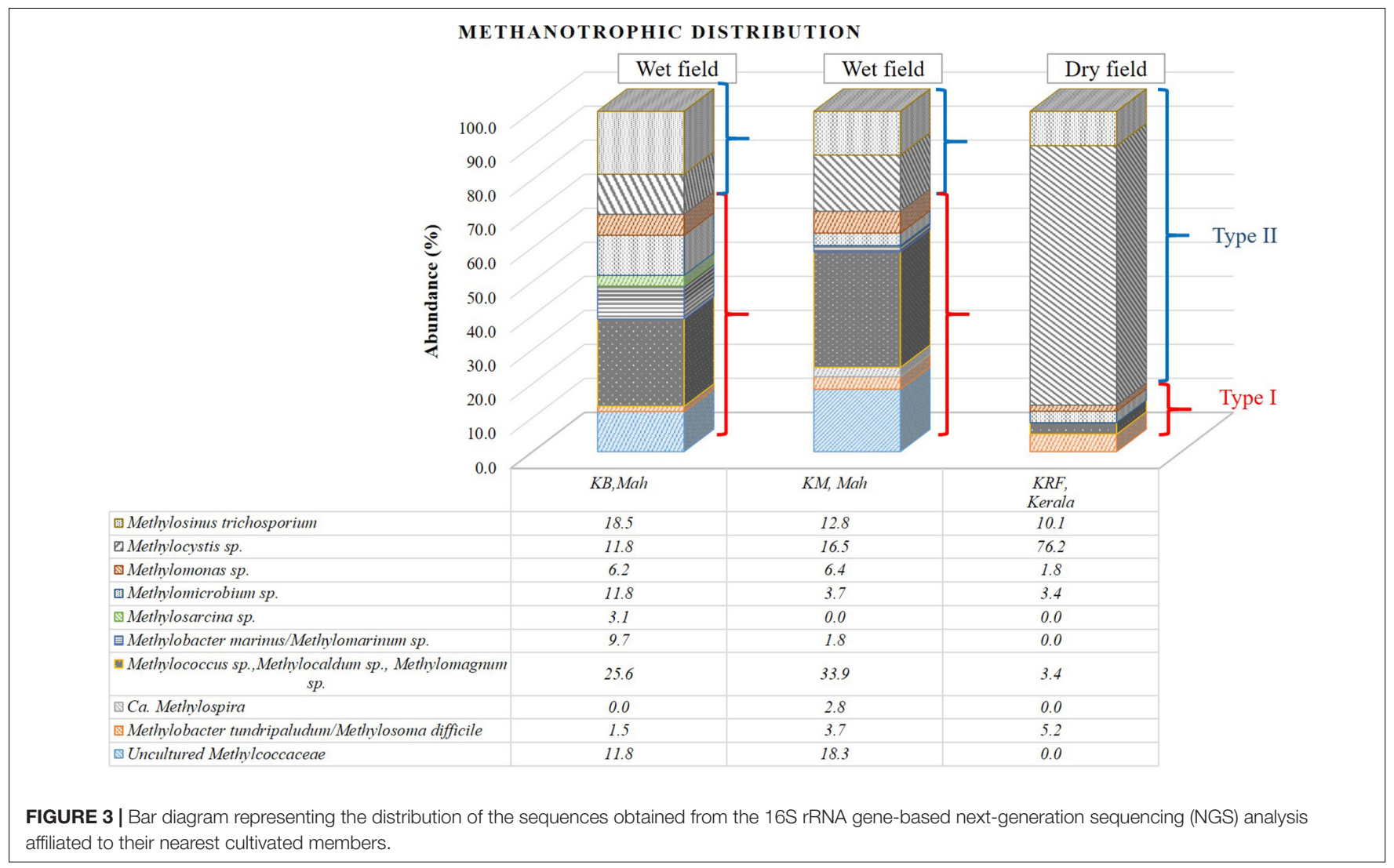

TABLE 2 | Total number of sequences of methanotrophs from 16S rRNA gene-based next-generation sequencing (NGS) analysis data.

\begin{tabular}{|c|c|c|c|}
\hline Species or lineage & Sequences $\mathrm{Kb}$ (wet field-rice growing) & Sequences KM (rice growing wet) & Sequences KRF (winter dry field) \\
\hline Methylococcaceae & 136 & 74 & 58 \\
\hline Methylocystaceae & 59 & 32 & 385 \\
\hline $\begin{array}{l}\text { Ratio of Methylococcaceae/ } \\
\text { Methylocystaceae }\end{array}$ & 2.3 & 2.3 & 0.20 \\
\hline
\end{tabular}

The morphological details of the strain RS1 are shown in Figure 4. Strain RS1 cells are motile pleomorphic bacilli with the dimensions of 1.0-4.0 $\mu \mathrm{m} \times 0.5-1 \mu \mathrm{m}$ (Figures 4A,B). Colonies of RS1 were white, circular, and butyrous in consistency (Figure 4C). The cells have Gram-negative character. The growth of strain RS1 in liquid medium was in the form of white turbidity that attained an OD of $0.15-0.25$ (Figure 4D).

After the complete $16 \mathrm{~S}$ rRNA gene (1,523 bp) was obtained using the sequenced draft genome, the 16S rRNA strain RS1 expressed the closest similarity to $98.69 \%$ with Methylomicrobium agile ATCC $3508^{\mathrm{T}}$. The complete $16 \mathrm{~S}$ rRNA gene sequence (1,523 bp) has been submitted to the NCBI database with the accession number MH764455.2. The 16S rRNA gene phylogenetic tree (Supplementary Figure 4A) of strain RS1 and related species showed a distinct phylogenetic position of strain RS1 from its closest type species M. agile strain ATCC $35068^{\mathrm{T}}$. Considering the reclassification suggested (Orata et al., 2018), Methylosarcina lacus, the next closest affiliate to strain RS1 has been renamed to Methylomicrobium lacus, thus reassuring that RS1 belongs to the genus Methylomicrobium.
The RS1 pmoA gene sequence expressed $94.01 \%$ similarity to its closest type species M. album strain ATCC $3303^{\mathrm{T}}$, reflected in the phylogenetic analysis (Supplementary Figure 4B).

\section{Whole Draft Genome Analysis of RS1}

The whole genome of RS1 is $4.73 \mathrm{Mbp}$ in size with a G+C content of 55\%. The NCBI accession number for the wholegenome sequence and the bio-project numbers are JAERVK01 and PRJNA690655, respectively. The general draft genome characteristics of strain RS1 are listed in Table 3. The ANIb, AAI, and DDH values between RS1 and its closest members genomes are $69-91,62-90$, and $18-44 \%$, respectively (Supplementary Table 3), which are lesser than the thresholds for prokaryotic species description (95\% for ANI and AAI while 70\% for DDH) (Kim et al., 2014). Additionally, the $98.69 \%$ similarity based on the complete 16SrRNA gene with the type species M. album strain ATCC $35068^{\mathrm{T}}$ is also lower than the $98.7 \%$ cutoff mentioned for a novel species (Sangal et al., 2016). Based on this analysis, we propose a new name for the putative novel species as 'Ca. Methylomicrobium oryzae' strain RS1. M. oryzae sp. nov. 


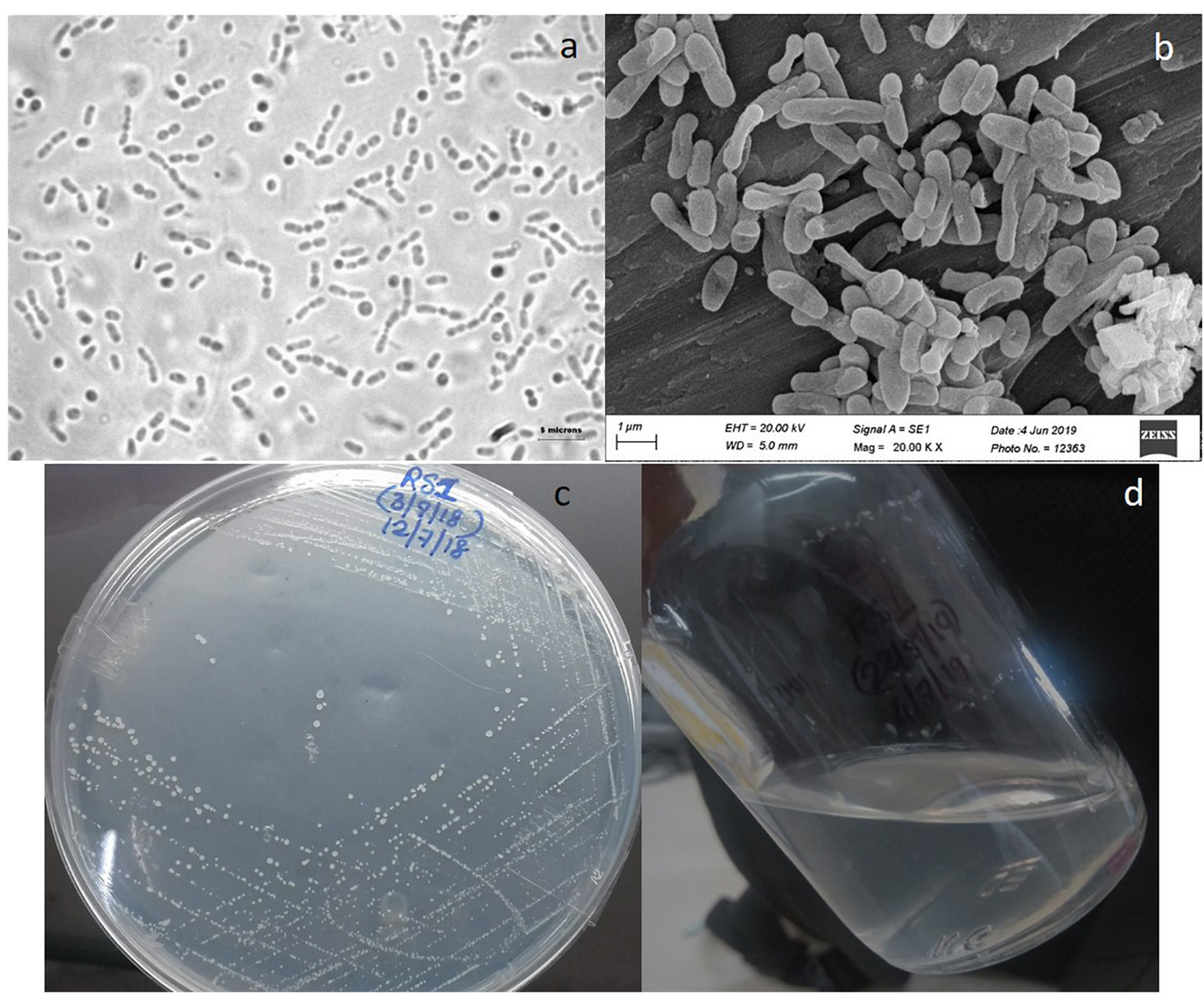

FIGURE 4 | Morphology of strain RS1: (a) live cells were observed under a phase-contrast microscope (Nikon 80i, Japan microscope with a camera) under 100x magnification with oil emulsion. (b) Culture observed under a scanning electron microscopy (SEM) (Zeiss model EVO-MA-15 SEM). (c) Colony morphology on solid nitrate mineral salts (NMS) medium. (d) RS1 forms whitish turbid suspension growth in liquid NMS medium.

(o.ry'zae. N.L. gen. n. oryzae), of rice, referring to isolation from rice plant.

\section{DISCUSSION}

\section{Highlights of the Method Including Advantages and Disadvantages Over the Traditional Method of Enrichment and Isolation of Methanotrophs}

Due to the various challenges, the cultivation of methanotrophs has been attempted by very few research groups in the world. The number of cultivated methanotrophs is far less than the as-yet-uncultivated ones (Hamilton et al., 2015). Despite all the knowledge regarding methanotroph cultivation, the isolation of novel methanotrophic taxa remains a challenging task (Dedysh and Dunfield, 2014).
In our approach, we used a medium (modified dil. NMS) that was modified from the dilute NMS medium for culturing of lake methanotrophs (Bussmann et al., 2004; Rahalkar et al., 2007; Deutzmann et al., 2014; Schink and Rahalkar, 2016). The dil. NMS medium was a modification of the original NMS medium described by Whittenbury et al. (1970). We modified the dil. NMS medium used for lake methanotrophs to cultivate rice field methanotrophs by increasing the amount of $\mathrm{KNO}_{3}$ to $0.25 \mathrm{~g} / \mathrm{L}$ (Pandit et al., 2016). The use of five times more nitrate $\left(\mathrm{KNO}_{3}\right)$ concentration in the modified dNMS medium as compared with the original one (Bussmann et al., 2004) was because rice field habitats are fertilized with nitrogenous fertilizers like urea or ammonium phosphates. Our group has used this medium in successfully isolating representatives of two novel Type I methanotroph genera (Pandit et al., 2018; Pandit and Rahalkar, 2019; Rahalkar et al., 2020) and new species (Rahalkar and Pandit, 2018; Khatri et al., 2019; Rahalkar et al., 2019) from Indian rice fields and wetland environments. 
TABLE 3 | Genomic features of Methylomicrobium RS1.

\begin{tabular}{ll}
\hline Traits & Values \\
\hline Genome size & $4.73 \mathrm{Mbp}$ \\
$\mathrm{G}+\mathrm{C}$ content & $55 \%$ \\
N50 & 233,876 \\
Proteins (according to NCBI) & 4,114 \\
Genes (according to NCBI) & 4,231 \\
tRNA, ncRNA & 45,4 \\
rRNA & 3 \\
Contigs & 69 \\
Bioproject number & PRJNA690655 \\
Sequencing platform used & Illumina HiSeq $2 \times 150$ \\
NCBI accession number & JAERVKO.1 \\
\hline
\end{tabular}

Additionally, we used serial dilutions, initially in serum bottles, followed by a second dilution series in microtiter plates. The first serial dilution culturing would give a chance to numerically dominant but slow-growing methanotrophs due to a long incubation of 6-8 weeks. In contrast, in traditional culturing, usually a single enrichment is set up, or dilutions are directly plated on plates (Dedysh and Dunfield, 2014). The single-enrichment series would allow only the growth of the fast-growing methanotrophs. Moreover, many methanotrophs are resistant to culturing on solid agar plates directly. The purpose of using a second dilution series was a separation of the diverse methanotrophs growing in the first dilution series bottles. The advantage of using microtiter plates for the enrichment of methanotrophs has been documented earlier (Bussmann et al., 2004; Bowman, 2006).

The first step of enrichment was from $10^{-1}$ to $10^{-10}$, followed by a second dilution series of up to $10^{-8}$. Preincubated rice field soils favored the cultivable methanotrophs to range from $10^{7}$ to $10^{9}$ (Escoffier et al., 1997). Most probable number (MPN)based studies on the rice rhizosphere soils of Uruguay and India revealed the methane-oxidizing bacteria (MOB) counts per gram of dry soil to be in the range $1.7 \times 10^{4}$ to $3.3 \times 10^{4}$ (Ferrando and Tarlera, 2009) and $5.5 \times 10^{8}$ cells (Dubey et al., 2003). In a study on the Italian rice field, the count of the methanotroph quantified with real-time PCR revealed that count was in the range of $2.5 \times 10^{6} \mathrm{MOB}$ per gram of fresh soil (Kolb et al., 2003). In our study, we have reported successful cultivation of methanotrophs from $10^{-2}$ to $10^{-8}$ dilutions, thus representing the MOB count to be in this range.

In the final step, we used the same medium with agarose for the separation of isolates and repeated the streaking and re-streaking. Methanotrophs are usually associated with other heterotrophic bacteria (Dedysh and Dunfield, 2014; Knief, 2015; Kalyuzhnaya et al., 2019). The heterotrophs sometimes thrive on the media components like agar, or the metabolites secreted by the methanotrophs like acetate, formate, lactate, and succinate (Bothe et al., 2002; Kalyuzhnaya et al., 2013); methanol (Wilkinson et al., 1974); formaldehyde (Bussmann et al., 2006); and exopolysaccharides (Koch et al., 2008; Dedysh et al., 2012). These heterotrophs form satellite colonies around the methanotrophic ones on solid growth media. The most challenging, laborious, and time-consuming task in methanotroph isolation is removing these satellite bacteria (Dedysh and Dunfield, 2014). Numerous methanotrophs cannot grow or poorly grow on agar (Bowman, 2006); therefore, a purified form of agar, i.e., agarose, was used in our prior studies (Rahalkar et al., 2007). Therefore, in our current method, we have used agarose to allow better growth on solid medium.

Although the current discussed method is little timeconsuming due to long incubation periods as compared with the traditional way (Dedysh and Dunfield, 2014), a relatively large number of methanotroph strains from various genera were isolated using the current method. For example, a total of 21 methanotrophs from four different genera were isolated from the Kerala rice field samples, which included including a putative novel species $C a$. M. oryzae KRF1, described in an earlier publication (Rahalkar et al., 2019; Khatri et al., 2020). In the current study, six methanotroph strains belonged to three genera, and a putative novel species $\mathrm{Ca}$. Methylomicrobium oryzae strain RS1 was from the Malegaon region. Cultivation studies on Japanese rice field samples had resulted in the isolation of 13 strains belonging to three different genera (Dianou et al., 2012). Similarly, a culturing experiment on Uruguay rice field methanotroph samples had resulted in culturing of strains from three genera (Ferrando and Tarlera, 2009).

\section{Comparison of the Cultured Community With Uncultured Methanotroph Members}

Rice fields are among the most important anthropogenic sources of atmospheric methane and contribute to $10 \%$ of the global methane emissions (Conrad, 2009). India leads the world in the rice production area with $\sim 43.7 \mathrm{~m}$ ha under rice cultivation and covers $28.6 \%$ of the world's rice cultivated area ${ }^{8}$. Indian rice fields emit less methane (3.9 Tg/year) (Ganesan et al., 2017), which is $\sim 15 \%$ of the global emissions from rice fields (25.6 Tg/year) (Yan et al., 2009). Methanotrophs present in rice rhizospheres have been estimated to oxidize about $20 \%$ of the produced methane (Conrad, 2009). The microbial ecology of methanotrophic bacteria from Indian rice fields of the Northern region (subtropical) has been studied mainly by culture-independent methods (Vishwakarma et al., 2009; Vishwakarma and Dubey, 2010a,b). However, significantly less is known about the cultural identity of methanotrophs from the tropical rice ecosystems. Cultivated methanotrophs from rice fields belong to the genera: Methylomonas, Methylobacter, Methylogaea, Methylomagnum, Methyloterricola, Methylocaldum, Methylocucumis, Methylocystis, and Methylosinus (Ferrando and Tarlera, 2009; Dianou et al., 2012; Pandit et al., 2016; Pandit and Rahalkar, 2018; Pandit et al., 2018; Khatri et al., 2019; Rahalkar et al., 2019). Growth curves of selected strains indicated that maximum growth of up to $0.15-0.2$ OD was achieved within 15 days. A recent carbon and nitrogen source optimization study using representative strains from Methylocystis, Methylosinus, Methylomicrobium, and Methylomonas showed a similar range growth when methane was used (Tays et al., 2018) (OD value increased up to 0.2 ). In order to use the strains for

\footnotetext{
${ }^{8}$ https://www.statista.com/statistics/765691/india-area-of-cultivation-for-rice/
} 
biotechnological purposes, it would be necessary to optimize the medium and conditions for optimal growth.

The sampling was done in the 80-90 days' period after transplantation in most of the cases, which marks the late flowering or grain formation stage. The highest methane oxidation activity has been reported at this stage from Indian soils (Vishwakarma et al., 2009). In the present study, among the cultivated species, the maximum species belonged to the genus Methylomonas, followed by Methylocystis or Methylosinus, as reported in a study from the Japanese rice fields (Dianou et al., 2012). Also, we report the cultivation of strains of $M$. ishizawai and $M$. oryzae, which have been typically isolated from rice fields (Khalifa et al., 2015; Pandit et al., 2018; Pandit and Rahalkar, 2019). Strain KRF4 (Supplementary Figure 3) showed characteristic fat oval-cylindrical cells, which were large-sized, identical to strains 114 and 175, isolated from the Philippines (Frindte et al., 2017).

We supported our study with $16 \mathrm{~S}$ rRNA gene-based NGS of three representative rice rhizosphere soils. The major players detected in the field $\mathrm{KB}$ were Methylomicrobium and Methylobacter from Type Ia methanotrophs, and Methylolobus and Methylomagnum (a new genus in the description) from Type Ib and Type II methanotrophs (Methylocystis and Methylosinus). The rice field KM showed the dominance of mainly Type Ib (Methylolobus and Methylomagnum) and Type II methanotrophs (Methylocystis and Methylosinus). KRF field showed the dominance of Methylocystaceae family, which could be due to the time of sampling, as the KRF sample was taken in December (December 2017) where the rice fields were dry, whereas the other two samples were taken in peak monsoon when the rice fields were completely waterlogged. In rice fields that undergo drying, it has been reported that Methylocystaceae forms a more abundant and constant population, whereas Methylococcaceae members are dynamic and are more diverse and active (Vishwakarma et al., 2009; Ma et al., 2013; Lüke et al., 2014; Leng et al., 2015 and references therein).

Comparison of the cultivated members with the members detected by metagenomics revealed that most of the dominant methanotrophic lineages detected in rice fields were cultivated. Together with the current cultivation study and our previous studies, we have broadened the culturable diversity of methanotrophs from Indian tropical rice fields by culturing from total of nine genera of methanotrophs.

The methanotrophic community detected in Indian rice field samples (KRF, KM, and $\mathrm{KB}$ ) was very similar to the methanotrophs seen in Vercelli, Italy. In a stable isotope study, the community was composed of Methylomonas, Methylobacter, Methylomicrobium, Methylocaldum, Methylococcus, Methylocystis, and Methylosinus (Shrestha et al., 2008). Similarly, in China, a very similar methanotroph community has been detected (Ma et al., 2013). The distribution of Methylococcaceae to Methylocystaceae in various tropical and subtropical regions has been found to be variable, and this was recently studied using $p m o A$ amplicon sequencing (Lüke et al., 2014). In this work, they compared the methanotroph population in tropical paddy fields distributed through the two main islands of Indonesia (Java and Sumatra) and from South Southern Vietnam (Tien Giang province) to the wetland rice fields located in the subtropical climate: the coastal area south of the Yangtze River Delta (Cixi, Zhejiang Province, China) and Vercelli Province, Italy (Lüke et al., 2014). The tropical wetlands showed the dominance of Methylococcaceae, in general (Type Ia and Type Ib together), whereas in the subtropical area, Type II methanotrophs were dominant. This was similar to our results where we found a dominance of Methylococcaceae (Types Ia and Ib) over Methylocystaceae in both the fields, which fall under the tropical regime. Our earlier documented study also showed the dominance of Methylococcaceae from Maharashtra rice fields (Pandit et al., 2016). At the same time, the studies from Northern parts of India (Varanasi) have documented the dominance of Methylocystaceae members (Vishwakarma et al., 2009) with subtropical weather. Also, type of soil and cultivation practices have been shown to impact the methanotroph community structure, as indicated by studies from Northern India (Vishwakarma et al., 2009; Vishwakarma and Dubey, 2010b). Hence, the differences in the community structure of methanotrophs observed could be due to several reasons stated above.

\section{Cultivation of Yet Uncultivated Taxa (Methylomicrobium)}

Despite indications of Methylomicrobium from the rice ecosystems studied worldwide, there had been no previous strains of Methylomicrobium isolated reported from rice field habitats. A recent study reported the presence of methanotrophic taxa distantly related to genus Methylomicrobium, Methylosarcina, Methylocaldum, and Methylocystis in six rice paddies studied across Taiwan (Shiau et al., 2018). The methane consumption was dominated by the Methylomicrobium/Methylosarcina like methanotrophs in the forest soils of Vercelli, Italy, as observed using the stable isotope probing-phospholipid fatty acid (SIPPLFA) profiling method (Mohanty et al., 2006). In yet another study of urea fertilized rice field from Vercelli, Italy, using the RNA-SIP methodology, the uptake of ${ }^{13} \mathrm{CH}_{4}$ was exclusively observed in the genera Methylomicrobium and Methylocaldum (Noll et al., 2008). The reported Methylomicrobium species, M. agile (Bowman et al., 1995), M. album (Bowman et al., 1993), Methylomicrobium alcaliphilum (Kalyuzhnaya et al., 2008), Methylomicrobium buryatense (Kaluzhnaya et al., 2001), Methylomicrobium japanense (Kalyuzhnaya et al., 2008), Methylomicrobium kenyense (Kalyuzhnaya et al., 2008), M. lacus (Kalyuzhnaya et al., 2005; Shrestha et al., 2008; Oren and Garrity, 2019), and Methylomicrobium pelagicum have been isolated from niches like freshwater swamp sediment, soda lake sediments, lake sediments, marine sediment, and estuarine sediments/waters. The novel member of Methylomicrobium, which we have isolated, could be one of the first members of Methylomicrobium, isolated from any rice field in the world.

Methanotrophs are natural methane mitigation agents. The methanotroph isolates isolated from native habitats such as rice fields enable us to use them as models for studying methane mitigation. The successful cultivation of methanotrophs from various natural habitats opens an avenue for various biotechnological applications. Problems associated with cultivation and obtaining fast growth as well as cryopreservation 
still limits their applications. The following applications have already been reported for methanotrophs. The production of polyhydroxyalkanoate (PHA) granules using Methylocystis and Methylosinus strains (Karthikeyan et al., 2015), and Methylomagnum (Luangthongkam, 2019); methanol using Methylomicrobium (Patel et al., 2020a), Methylosinus (Patel et al., 2016), Methylomonas (Patel et al., 2018b), and Methylocystis (Patel et al., 2018a); and carotenoids using Methylomonas (Ye et al., 2007) etc. can be analyzed. In addition to these applications, other applications such as bioremediation, biosensor preparation, denitrification, microbial fuel cells, oxidation of alkanes and aromatic compounds, and utilization of $\mathrm{CO}_{2}$ (Chistoserdova, 2018) can also be explored.

In conclusion, our method resulted in the isolation and cultivation of uncultured, dominant, and environmentally significant methanotrophs from Indian rice fields. The cultivation strategy where we used a low-nutrient medium, two series of serial dilutions, and long-term incubations could have been an essential strategy for the isolation. We cultivated methanotrophs from rice field soils from India using a culturing method with a double-step dilution till extinction cultivation followed by isolation on solid plates. The $\sim 29$ strains belonged to seven genera: Methylomonas (18), Methylocaldum (one), Methylomicrobium (one), Methylomagnum (one), and Methylocucumis (one) from Type I methanotrophs (Methylococcaceae), and Methylocystis (three) and Methylosinus (five) from Type II methanotrophs (Methylocystaceae). Cultureindependent molecular analyses using the V3-V4 amplicon sequencing showed that methanotrophs from nine or 10 genera were present in rice rhizosphere samples. The cultured putative novel member of Methylomicrobium represents the first cultured Methylomicrobium, detected in rice fields. The isolates obtained in this study would be used as model or reference strains to study methanotrophy in rice fields and could be used for further environmental and biotechnological applications.

\section{DATA AVAILABILITY STATEMENT}

The datasets generated for this study can be found in online repositories. The names of the repository/repositories and accession number(s) can be found in the article/ Supplementary Material.

\section{AUTHOR CONTRIBUTIONS}

MR designed the experiments, collected the samples, guided all the experiments, did the sequence analysis, 16S rRNA gene-based NGS analysis, phylogenetic analysis, assisted in the figures, and wrote the manuscript. PP and KK performed the enrichment, isolation of the organisms, subculturing and maintenance of cultures, DNA extraction, and sample preparation for sequencing and some part of the blast analysis. JM did the subculturing of cultures and helped in DNA extraction, etc. RB did the sampling, performed 16S rRNA gene-based NGS analysis and phylogenetic analysis, and prepared the figures for phylogenetic trees. All authors reviewed the manuscript and approved the final version.

\section{FUNDING}

MR acknowledges the Department of Science and Technology, DST, SERB (EMR/2017/002817) for the funds and the Department of Biotechnology for the funds under the DBT BioCARe programme (BT/BioCARe/06/840/2012). PP acknowledges DST (SR/WOS-A/LS-410/2017) for providing the female scientists fellowship funds. KK acknowledges CSIR for providing junior research and senior research fellowship. JM is thankful to SERB for the JRF fellowship under the (EMR/2017/002817) project. RB is thankful to BAIF Development Research Foundation for the overall support from his institute.

\section{ACKNOWLEDGMENTS}

We are extremely thankful to the rice farmers for allowing us to collect the rice field samples.

\section{SUPPLEMENTARY MATERIAL}

The Supplementary Material for this article can be found online at: https://www.frontiersin.org/articles/10.3389/fmicb.2021. 669244/full\#supplementary-material

Supplementary Figure 1 | Maximum-likelihood bootstrap tree of the 16S rRNA gene sequences of Methylococcaceae methanotrophic isolates in comparison with those of other clones obtained from $\mathrm{KB}$ and $\mathrm{KM}$ rice rhizosphere samples. The number in front of each denotes the number of sequences from that sample, e.g., KB15 (15 partial 16S rRNA gene sequences from KB sample). The evolutionary analyses were conducted in MEGA7. The bar represents $1 \%$ divergence. The tree was drawn to scale, with branch lengths in the same units as those of the evolutionary distances used to infer the phylogenetic tree. The evolutionary distances were computed using the Maximum Composite Likelihood method and are in the units of the number of base substitutions per site. The analysis involved 271 nucleotide sequences. All positions containing gaps and missing data were eliminated. There were a total of 134 positions in the final dataset.

Supplementary Figure 2 | Methylocystaceae family phylogenetic tree of the V3-V4 sequences derived from the 16S rRNA gene-based next generation sequencing (NGS) analysis using the KB and the KM samples. The number against the sample name represents the number of sequences retrieved for that sample. The tree also consists of methanotrophic isolate sequences for co-relation with the sequences. The phylogenetic tree was constructed using MEGAX, and the bar represents 1\% divergence. The analysis involved 104 nucleotide sequences. All positions containing gaps and missing data were eliminated.

Supplementary Figure 3 | Growth of isolates on solid media plates and their respective phase-contrast images with 1,000 $\times$ magnification. The bar represents $5 \mu \mathrm{m}$.

Supplementary Figure 4 | (A) Maximum-likelihood 1,000 bootstrap tree of the 16S rRNA gene sequence of strain RS1 in comparison with the closely associated Methylococcaceae bacteria. The phylogenetic tree was constructed using MEGA $X$ and analyzed based on the Tamura-Nei model. Bar represented $1 \%$ divergence. (B) Maximum-likelihood 1,000 bootstrap tree of the partial pmoA nucleotide sequence of strain RS1 in comparison with the pmoA gene sequences of closely related Type I methanotrophs. The evolutionary history was inferred by using the maximum-likelihood method based on the Tamura-Nei model with MEGA X. The bar representing a $5 \%$ divergence.

Supplementary Material | Growth curves and methane oxidation of the cultures. 


\section{REFERENCES}

Al Hasin, A., Gurman, S. J., Murphy, L. M., Perry, A., Smith, T. J., and Gardiner, P. H. E. (2010). Remediation of chromium (VI) by a methane-oxidizing bacterium. Environ. Sci. 44, 400-405. doi: 10.1021/es901723c

Antony, C. P., Doronina, N. V., Boden, R., Trotsenko, Y. A., Shouche, Y. S., and Murrell, J. C. (2012). Methylophaga lonarensis sp. nov., a moderately haloalkaliphilic methylotroph isolated from the soda lake sediments of a meteorite impact crater. Int. J. Syst. Evolut. Microbiol. 62, 1613-1618. doi: 10.1099/ijs.0.035089-0

Bothe, H., Jensen, K. M., Mergel, A., Larsen, J., Jørgensen, C., Bothe, H., et al. (2002). Heterotrophic bacteria growing in association with Methylococcus capsulatus (Bath) in a single cell protein production process. Appl. Microbiol. Biotechnol. 59, 33-39. doi: 10.1007/s00253-002-0964-1

Bowman, J. (2006). The methanotrophs-the families methylococcaceae and methylocystaceae. Prokaryotes 5, 266-289. doi: 10.1007/0-387-30745-1_15

Bowman, J. (2011). "Approaches for the characterization and description of novel methanotrophic bacteria," in Methods in Methane Metabolism, Part B Methanotrophy Methods in Enzymology, eds A. C. Rosenzweig and S. W. Ragsdale (Amsterdam: Elsevier), 45-62. doi: 10.1016/b978-0-12-386905-0. 00004-8

Bowman, J. P., McCammon, S. A., and Skerrat, J. H. (1997). Methylosphaera hansonii gen. nov., sp. nov., a psychrophilic, group I methanotroph from Antarctic marine-salinity, meromictic lakes. Microbiology 143, 1451-1459. doi: 10.1099/00221287-143-4-1451

Bowman, J. P., Sly, L. I., and Stackebrandt, E. (1995). The phylogenetic position of the family Methylococcaceae. Int. J. Syst. Evolut. Microbiol. 45, 182-185. doi: 10.1099/00207713-45-1-182

Bowman, J. P., Sly, L. I., Nichols, P. D., and Hayward, A. C. (1993). Revised taxonomy of the methanotrophs: description of Methylobacter gen. nov., emendation of Methylococcus, validation of Methylosinus and Methylocystis species, and a proposal that the family Methylococcaceae includes only the group I methanotrophs. Int. J. Syst. Evolut. Microbiol. 43, 735-753. doi: 10.1099/ 00207713-43-4-735

Bussmann, I., Pester, M., Brune, A., and Schink, B. (2004). Preferential cultivation of type II methanotrophic bacteria from littoral sediments (Lake Constance). FEMS Microbiol. Ecol. 47, 179-189. doi: 10.1016/s0168-6496(03)00260-5

Bussmann, I., Rahalkar, M., and Schink, B. (2006). Cultivation of methanotrophic bacteria in opposing gradients of methane and oxygen. FEMS Microbiol. Ecol. 56, 331-344. doi: 10.1111/j.1574-6941.2006.00076.x

Chistoserdova, L. (2018). Applications of methylotrophs: can single carbon be harnessed for biotechnology? Curr. Opin. Biotechnol. 50, 189-194. doi: 10.1016/ j.copbio.2018.01.012

Conrad, R. (2009). The global methane cycle: recent advances in understanding the microbial processes involved. Environ. Microbiol. Rep. 1, 285-292. doi: 10.1111/j.1758-2229.2009.00038.x

Dedysh, S. N. (2009). Exploring methanotroph diversity in acidic northern wetlands: molecular and cultivation-based studies. Microbiology 78, 655-669. doi: $10.1134 / \mathrm{s} 0026261709060010$

Dedysh, S. N., and Dunfield, P. F. (2014). "Cultivation of methanotrophs," in Hydrocarbon and Lipid Microbiology Protocols, eds T. McGenity, K. Timmis, and B. Nogales (Berlin: Springer), 231-247. doi: 10.1007/8623_2014_14

Dedysh, S. N., and Knief, C. (2018). "Diversity and phylogeny of described aerobic methanotrophs," in Methane Biocatalysis: Paving the way to sustainability, eds M. G. Kalyuzhnaya and X.-H. Xing (Cham: Springer), 17-42. doi: 10.1007/9783-319-74866-5_2

Dedysh, S. N., Kulichevskaya, I. S., Serkebaeva, Y. M., Mityaeva, M. A., Sorokin, V. V., Suzina, N. E., et al. (2012). Bryocella elongata gen. nov., sp. nov., a member of subdivision 1 of the Acidobacteria isolated from a methanotrophic enrichment culture, and emended description of Edaphobacter aggregans Koch et al., 2008. Int. J. Syst. Evolut. Microbiol. 62, 654-664. doi: 10.1099/ijs.0.031 898-0

Deutzmann, J. S., Hoppert, M., and Schink, B. (2014). Characterization and phylogeny of a novel methanotroph, Methyloglobulus morosus gen. nov., spec. nov. Syst. Appl. Microbiol. 37, 165-169. doi: 10.1016/j.syapm.2014. 02.001

Dianou, D., Ueno, C., Ogiso, T., Kimura, M., and Asakawa, S. (2009). Diversity of cultivable methane-oxidizing bacteria in microsites of a rice paddy field: investigation by cultivation method and fluorescence in situ hybridization (FISH). Microbes Environ. 27, 278-287. doi: 10.1264/jsme2.me11327

Dianou, D., Ueno, C., Ogiso, T., Kimura, M., and Asakawa, S. (2012). Diversity of cultivable methane-oxidizing bacteria in microsites of a rice paddy field: investigation by cultivation method and fluorescence in situ hybridization (FISH). Microbes Environ. 27, 278-287. doi: 10.1264/jsme2.ME11327

Dubey, S., Padmanabhan, P., Purohit, H., and Upadhyay, S. (2003). Tracking of methanotrophs and their diversity in paddy soil: a molecular approach. Curr. Sci. 85, 92-95.

Dunfield, P. F., Khmelenina, V. N., Suzina, N. E., Trotsenko, Y. A., and Dedysh, S. N. (2003). Methylocella silvestris sp. nov., a novel methanotroph isolated from an acidic forest cambisol. Int. J. Syst. Evolut. Microbiol. 53, 1231-1239. doi: 10.1099/ijs.0.02481-0

Escoffier, S., Le Mer, J., and Roger, P.-A. (1997). Enumeration of methanotrophic bacteria in ricefield soils by plating and MPN techniques: a critical approach. Eur. J. Soil Biol. 33, 41-52.

Ettwig, K. F., Butler, M. K., Le Paslier, D., Pelletier, E., Mangenot, S., Kuypers, M. M., et al. (2010). Nitrite-driven anaerobic methane oxidation by oxygenic bacteria. Nature 464, 543-548. doi: 10.1038/nature08883

Ferrando, L., and Tarlera, S. (2009). Activity and diversity of methanotrophs in the soil-water interface and rhizospheric soil from a flooded temperate rice field. J. Appl. Microbiol. 106, 306-316. doi: 10.1111/j.1365-2672.2008.04004.x

Frenzel, P. (2012). "Plant-associated methane oxidation in rice fields and wetlands," in Advances in Microbial Ecology, ed. B. Schink (Dordrecht: Kluwer Academic).

Frindte, K., Maarastawi, S. A., Lipski, A., Hamacher, J., and Knief, C. (2017). Characterization of the first rice paddy cluster I isolate, Methyloterricola oryzae gen. nov., sp. nov. and amended description of Methylomagnum ishizawai. Int. J. Syst. Evolut. Microbiol. 67, 4507-4514. doi: 10.1099/ijsem.0.002319

Ganesan, A., Rigby, M., Lunt, M. F., Parker, R. J., Boesch, H., Goulding, N., et al. (2017). Atmospheric observations show accurate reporting and little growth in India's methane emissions. Nat. Commun. 8:836. doi: 10.1038/s41467-01700994-7

Hamilton, R., Kits, K. D., Ramonovskaya, V. A., Rozova, O. N., Yurimoto, H., Iguchi, H., et al. (2015). Draft genomes of gammaproteobacterial methanotrophs isolated from terrestrial ecosystems. Genome Announc. 3, 1-3.

Hanson, R. S., and Hanson, T. E. (1996). Methanotrophic bacteria. Microbiol. Mol. Biol. Rev. 60, 439-471. doi: 10.1128/mmbr.60.2.439-471.1996

Hirayama, H., Suzuki, Y., Abe, M., Miyazaki, M., Makita, H., Inagaki, F., et al. (2011). Methylothermus subterraneus sp. nov., a moderately thermophilic methanotroph isolated from a terrestrial subsurface hot aquifer. Int. J. Syst. Evolut. Microbiol. 61, 2646-2653. doi: 10.1099/ijs.0.028092-0

Kaluzhnaya, M., Khmelenina, V., Eshinimaev, B., Suzina, N., Nikitin, D., Solonin, A., et al. (2001). Taxonomic characterization of new alkaliphilic and alkalitolerant methanotrophs from soda lakes of the Southeastern Transbaikal region and description of Methylomicrobium buryatense sp. nov. Syst. Appl. Microbiol. 24, 166-176. doi: 10.1078/0723-2020-00028

Kalyuzhnaya, M. G., Gomez, O. A., and Murrell, J. C. (2019). "The methane-oxidizing bacteria (methanotrophs)," in Taxonomy, Genomics And Ecophysiology Of Hydrocarbon-Degrading Microbes, ed. T. J. McGenity (Cham: Springer International Publishing), 1-34. doi: 10.1007/978-3-319-600536_10-1

Kalyuzhnaya, M. G., Stolyar, S. M., Auman, A. J., Lara, J. C., Lidstrom, M. E., and Chistoserdova, L. (2005). Methylosarcina lacus sp. nov., a methanotroph from Lake Washington, Seattle, USA, and emended description of the genus Methylosarcina. Int. J. Syst. Evolut. Microbiol. 55, 2345-2350. doi: 10.1099/ijs.0. 63405-0

Kalyuzhnaya, M. G., Yang, S., Rozova, O. N., Smalley, N. E., Clubb, J., Lamb, A., et al. (2013). Highly efficient methane biocatalysis revealed in a methanotrophic bacterium. Nat. Commun. 4:2785. doi: 10.1038/ncomms3785

Kalyuzhnaya, M., Khmelenina, V., Eshinimaev, B., Sorokin, D. Y., Fuse, H., Lidstrom, M., et al. (2008). Reclassification and emended description of halo (alkali) philic and halo (alkali) tolerant methanotrophs of genera Methylomicrobium and Methylobacter. Int. J. Syst. Evolut. Microbiol. 58, 591596. doi: 10.1099/ijs.0.65317-0

Karthikeyan, O. P., Chidambarampadmavathy, K., Cires, S., and Heimann, K. (2015). Review of sustainable methane mitigation and biopolymer production. Crit. Rev. Environ. Sci. Technol. 45, 1579-1610. doi: 10.1080/10643389.2014. 966422 
Khalifa, A., Lee, C. G., Ogiso, T., Ueno, C., Dianou, D., Demachi, T., et al. (2015). Methylomagnum ishizawai gen. nov., sp. nov., a mesophilic type I methanotroph isolated from rice rhizosphere. Int. J. Syst. Evolut. Microbiol. 65, 3527-3534. doi: 10.1099/ijsem.0.000451

Khatri, K., Mohite, J. A., Pandit, P. S., Bahulikar, R. A., and Rahalkar, M. C. (2019). Description of 'Ca. Methylobacter oryzae' KRF1, a novel species from the environmentally important Methylobacter clade 2. Antonie Van Leeuwenhoek 113, 729-735. doi: 10.1007/s10482-019-01369-2

Khatri, K., Mohite, J. A., Pandit, P. S., Bahulikar, R. A., and Rahalkar, M. C. (2020). Description of 'Ca. Methylobacter oryzae'KRF1, a novel species from the environmentally important Methylobacter clade 2. Antonie Van Leeuwenhoek 113, 729-735.

Khatri, K., Mohite, J., Pandit, P., Bahulikar, R. A., and Rahalkar, M. C. (2021). Isolation, description and genome analysis of a putative novel Methylobacter Species ('Ca. Methylobacter coli') isolated from the faeces of a blackbuck (indian antelope). Microbiol. Res. 12, 513-523. doi: 10.3390/microbiolres1202 0035

Kim, H. G., Han, G. H., Eom, C. Y., and Kim, S. W. (2008). Isolation and taxonomic characterization of a novel type I methanotrophic bacterium. J. Microbiol. 46, 45-50. doi: 10.1007/s12275-008-0017-2

Kim, M., Oh, H.-S., Park, S.-C., and Chun, J. (2014). Towards a taxonomic coherence between average nucleotide identity and 16S rRNA gene sequence similarity for species demarcation of prokaryotes. Int. J. Syst. Evolut. Microbiol. 64, 346-351. doi: 10.1099/ijs.0.059774-0

Knief, C. (2015). Diversity and habitat preferences of cultivated and uncultivated aerobic methanotrophic bacteria evaluated based on pmoA as molecular marker. Front. Microbiol. 6:1346. doi: 10.3389/fmicb.2015.01346

Koch, I. H., Gich, F., Dunfield, P. F., and Overmann, J. (2008). Edaphobacter modestus gen. nov., sp. nov., and Edaphobacter aggregans sp. nov., acidobacteria isolated from alpine and forest soils. Int. J. Syst. Evolut. Microbiol. 58, 11141122. doi: 10.1099/ijs.0.65303-0

Kolb, S., Knief, C., Stubner, S., and Conrad, R. (2003). Quantitative detection of methanotrophs in soil by novel pmoA-targeted real-time PCR assays. Appl. Environ. Microbiol. 69, 2423-2429. doi: 10.1128/aem.69.5.2423-2429. 2003

Kumar, S., Stecher, G., and Tamura, K. (2016). MEGA7: molecular evolutionary genetics analysis version 7.0 for bigger datasets. Mol. Biol. Evolut. 33, 18701874. doi: $10.1093 / \mathrm{molbev} / \mathrm{msw} 054$

Kumar, S., Stecher, G., Li, M., Knyaz, C., and Tamura, K. (2018). MEGA X: molecular evolutionary genetics analysis across computing platforms. Mol. Biol. Evolut. 35, 1547-1549. doi: 10.1093/molbev/msy096

Leng, L., Chang, J., Geng, K., Lu, Y., and Ma, K. (2015). Uncultivated Methylocystis species in paddy soil include facultative methanotrophs that utilize acetate. Microbial Ecol. 70, 88-96. doi: 10.1007/s00248-014-0540-0

Luangthongkam, P. (2019). Biosynthesis Of Polyhydroxyalkanoates (Phas) In Methane-Utilizing Mixed Cultures. Ph.D. thesis. St Lucia QLD: The University of Queensland.

Lüke, C. (2010). Molecular Ecology And Biogeography Of Methanotrophic Bacteria In Wetland Rice Fields. doctoral Dissertation. Marburg: Max-Planck-Institut für terrestrische Mikrobiologie.

Lüke, C., Frenzel, P., Ho, A., Fiantis, D., Schad, P., Schneider, B., et al. (2014). Macroecology of methane-oxidizing bacteria: the $\beta$-diversity ofpmoA genotypes in tropical and subtropical rice paddies. Environ. Microbiol. 16, 72-83. doi: 10.1111/1462-2920.12190

Lüke, C., Krause, S., Cavigiolo, S., Greppi, D., Lupotto, E., and Frenzel, P. (2010). Biogeography of wetland rice methanotrophs. Environ. Microbiol. 12, 862-872. doi: 10.1111/j.1462-2920.2009.02131.x

Ma, K., Conrad, R., and Lu, Y. (2013). Dry/wet cycles change the activity and population dynamics of methanotrophs in rice field soil. Appl. Environ. Microbiol. 79, 4932-4939. doi: 10.1128/aem.00850-13

Mohanty, S. R., Bodelier, P. L., Floris, V., and Conrad, R. (2006). Differential effects of nitrogenous fertilizers on methane-consuming microbes in rice field and forest soils. Appl. Environ. Microbiol. 72, 1346-1354. doi: 10.1128/AEM.72.2. 1346-1354.2006

Noll, M., Frenzel, P., and Conrad, R. (2008). Selective stimulation of type I methanotrophs in a rice paddy soil by urea fertilization revealed by RNA-based stable isotope probing. FEMS Microbiol. Ecol. 65, 125-132. doi: 10.1111/j.15746941.2008.00497.x
Orata, F. D., Kits, K. D., and Stein, L. Y. (2018). Complete genome sequence of methylomonas denitrificans strain FJG1, an obligate aerobic methanotroph that can couple methane oxidation with denitrification. Genome Announc. 6:2.

Oremland, R. S., and Culbertson, C. W. (1992). Importance of methane-oxidizing bacteria in the methane budget as revealed by the use of a specific inhibitor. Nature 356:6368.

Oren, A., and Garrity, G. (2019). List of new names and new combinations previously effectively, but not validly, published. Int. J. Syst. Evolut. Microbiol. 69, 2627-2629.

Oswald, K., Milucka, J., Brand, A., Hach, P., Littmann, S., Wehrli, B., et al. (2016). Aerobic gammaproteobacterial methanotrophs mitigate methane emissions from oxic and anoxic lake waters. Limnol. Oceanogr. 61, S101-S118.

Pandit, P. S., and Rahalkar, M. C. (2019). Renaming of 'Candidatus Methylocucumis oryzae' as Methylocucumis oryzae gen. nov., sp. nov., a novel Type I methanotroph isolated from India. Antonie Van Leeuwenhoek 112, 955-959. doi: 10.1007/s10482-018-01218-8

Pandit, P. S., Hoppert, M., and Rahalkar, M. C. (2018). Description of 'Candidatus Methylocucumis oryzae, a novel Type I methanotroph with large cells and pale pink colour, isolated from an Indian rice field. Antonie Van Leeuwenhoek 111, 2473-2484. doi: 10.1007/s10482-018-1136-3

Pandit, P. S., Rahalkar, M. C., Dhakephalkar, P. K., Ranade, D. R., Pore, S., Arora, P., et al. (2016). Deciphering community structure of methanotrophs dwelling in rice rhizospheres of an Indian rice field using cultivation and cultivationindependent approaches. Microbial Ecol. 71, 634-644. doi: 10.1007/s00248015-0697-1

Pandit, P., and Rahalkar, M. C. (2018). Renaming of 'Candidatus Methylocucumis oryzae' as Methylocucumis oryzae gen. nov., sp. nov., a novel Type I methanotroph isolated from India. Antonie Van Leeuwenhoek 112, 955-959.

Patel, S. K. S., Gupta, R. K., Kondaveeti, S., Otari, S. V., Kumar, A., Kalia, V. C., et al. (2020a). Conversion of biogas to methanol by methanotrophs immobilized on chemically modified chitosan. Bioresour. Technol. 315:123791. doi: 10.1016/j. biortech.2020.123791

Patel, S. K. S., Jeon, M. S., Gupta, R. K., Jeon, Y., Kalia, V. C., Kim, S. C., et al. (2019). Hierarchical macroporous particles for efficient whole-cell immobilization: application in bioconversion of greenhouse gases to methanol. ACS Appl. Mater. Interfaces 11, 18968-18977. doi: 10.1021/acsami.9b03420

Patel, S. K. S., Kalia, V. C., Joo, J. B., Kang, Y. C., and Lee, J.-K. (2020b). Biotransformation of methane into methanol by methanotrophs immobilized on coconut coir. Bioresour. Technol. 297:122433. doi: 10.1016/j.biortech.2019. 122433

Patel, S. K. S., Kondaveeti, S., Otari, S. V., Pagolu, R. T., Jeong, S. H., Kim, S. C., et al. (2018a). Repeated batch methanol production from a simulated biogas mixture using immobilized Methylocystis bryophila. Energy 145, 477-485. doi: 10.1016/j.energy.2017.12.142

Patel, S. K. S., Kumar, V., Mardina, P., Li, J., Lestari, R., Kalia, V. C., et al. (2018b). Methanol production from simulated biogas mixtures by co-immobilized Methylomonas methanica and Methylocella tundrae. Bioresour. Technol. 263, 25-32. doi: 10.1016/j.biortech.2018.04.096

Patel, S. K. S., Selvaraj, C., Mardina, P., Jeong, J.-H., Kalia, V. C., Kang, Y. C., et al. (2016). Enhancement of methanol production from synthetic gas mixture by Methylosinus sporium through covalent immobilization. Appl. Energy 171, 383-391. doi: 10.1016/j.apenergy.2016.03.022

Pester, M., Friedrich, M. W., Schink, B., and Brune, A. (2004). pmoA-based analysis of methanotrophs in a littoral lake sediment reveals a diverse and stable community in a dynamic environment. Appl. Environ. Microbiol. 70, 3138-3142. doi: 10.1128/aem.70.5.3138-3142.2004

Pol, A., Heijmans, K., Harhangi, H. R., Tedesco, D., Jetten, M. S. M., and Op den Camp, H. J. M. (2007). Methanotrophy below $\mathrm{pH} 1$ by a new Verrucomicrobia species. Nature 450, 874-878. doi: 10.1038/nature06222

Pytlak, A., Kuzniar, A., and Stepniewska, Z. (2012). pmoA based detection of methanotrophic bacteria in coal-bed rocks of the Lublin coal basin. Acta Agrophys. 19, 403-413.

Qiu, Q., Noll, M., Abraham, W. R., Lu, Y., and Conrad, R. (2008). Applying stable isotope probing of phospholipid fatty acids and rRNA in a Chinese rice field to study activity and composition of the methanotrophic bacterial communities in situ. ISME J. 2, 602-614. doi: 10.1038/ismej.2 008.34 
Rahalkar, M. (2007). Aerobic Methanotrophic Bacterial Communities From Sediments Of Lake Constance. Ph.D. thesis. Konstanz: University of Konstanz.

Rahalkar, M. C., and Pandit, P. (2018). Genome-based insights into a putative novel Methylomonas species (strain $\mathrm{Kb} 3$ ), isolated from an Indian rice field. Gene Rep. 13, 9-13. doi: 10.1016/j.genrep.2018.08.004

Rahalkar, M. C., Khatri, K., Mohite, J., Pandit, P., and Bahulikar, R. (2020). A novel Type I methanotroph Methylolobus aquaticus gen. nov. sp. nov. isolated from a tropical wetland. Antonie Van Leeuwenhoek 113, 959-971.

Rahalkar, M. C., Khatri, K., Pandit, P. S., and Dhakephalkar, P. K. (2019). A putative novel Methylobacter member (KRF1) from the globally important Methylobacter clade 2: cultivation and salient draft genome features. Antonie Van Leeuwenhoek 112, 1399-1408. doi: 10.1007/s10482-019-01262-y

Rahalkar, M., Bussmann, I., and Schink, B. (2007). Methylosoma difficile gen. nov., sp. nov., a novel methanotroph enriched by gradient cultivation from littoral sediment of Lake Constance. Int. J. Syst. Evolut. Microbiol. 57, 1073-1080. doi: 10.1099/ijs.0.64574-0

Reim, A., Luke, C., Krause, S., Pratscher, J., and Frenzel, P. (2012). One millimetre makes the difference: high-resolution analysis of methane-oxidizing bacteria and their specific activity at the oxic-anoxic interface in a flooded paddy soil. ISME J. 6, 2128-2139. doi: 10.1038/ismej.2012.57

Sangal, V., Goodfellow, M., Jones, A. L., Schwalbe, E. C., Blom, J., Hoskisson, P. A., et al. (2016). Next-generation systematics: an innovative approach to resolve the structure of complex prokaryotic taxa. Sci. Rep. 6, 1-12.

Schink, B., and Rahalkar, M. C. (2016). "Genus methylosoma rahalkar, bussmann and schink 2007, 1078VP," in Bergey's Manual of Systematics of Archaea and Bacteria, ed. W. Whitman (Hoboken, NJ: John Wliey and Sons). doi: 10.1002/ 9781118960608.gbm01415

Shiau, Y.-J., Cai, Y., Jia, Z., Chen, C.-L., and Chiu, C.-Y. (2018). Phylogenetically distinct methanotrophs modulate methane oxidation in rice paddies across Taiwan. Soil Biol. Biochem. 124, 59-69. doi: 10.1016/j.soilbio.2018.05.025

Shrestha, M., Abraham, W. R., Shrestha, P. M., Noll, M., and Conrad, R. (2008). Activity and composition of methanotrophic bacterial communities in planted rice soil studied by flux measurements, analyses of pmoA gene and stable isotope probing of phospholipid fatty acids. Environ. Microbiol. 10, 400-412. doi: $10.1111 /$ j.1462-2920.2007.01462.x

Strong, P. J., Xie, S., and Clarke, W. P. (2015). Methane as aresource: can the methanotrophs add value? Environ. Sci. Technol. 49, 4001-4018. doi: 10.1021/ es504242n

Tamura, K., and Nei, M. (1993). Estimation of the number of nucleotide substitutions in the control region of mitochondrial DNA in humans and chimpanzees. Mol. Biol. Evolut. 10, 512-526.

Tavormina, P. L., Hatzenpichler, R., McGlynn, S., Chadwick, G., Dawson, K. S., Connon, S. A., et al. (2015). Methyloprofundus sedimenti gen. nov., sp. nov., an obligate methanotroph from ocean sediment belonging to the 'deep seal'clade of marine methanotrophs. Int. J. Syst. Evolut. Microbiol. 65, 251-259. doi: 10.1099/ijs.0.062927-0
Tays, C., Guarnieri, M. T., Sauvageau, D., and Stein, L. Y. (2018). Combined effects of carbon and nitrogen source to optimize growth of proteobacterial methanotrophs. Front. Microbiol. 9:2239. doi: 10.3389/fmicb.2018.02239

Vishwakarma, P., and Dubey, S. K. (2010a). Diversity of methanotrophs in ureafertilized tropical rice agroecosystem. Indian J. Microbiol. 50, 205-211. doi: 10.1007/s12088-010-0040-y

Vishwakarma, P., and Dubey, S. K. (2010b). DNA microarray analysis targeting pmoA gene reveals diverse community of methanotrophs in the rhizosphere of tropical rice soils. Curr. Sci. 99, 1090-1095.

Vishwakarma, P., Dumont, M. G., Bodrossy, L., Stralis-Pavese, N., Murrell, J. C., and Dubey, S. K. (2009). Ecological and molecular analyses of the rhizospheric methanotroph community in tropical rice soil: effect of crop phenology and land-use history. Curr. Sci. 96, 1082-1089.

Whittenbury, R., Phillips, K. C., and Wilkinson, J. F. (1970). Enrichment, isolation and some properties of methane utilising bacteria. J. Gen. Microbiol. 61, 205218. doi: 10.1099/00221287-61-2-205

Wilkinson, T. G., Topiwala, H., and Hamer, G. (1974). Interactions in a mixed bacterial population growing on methane in continuous culture. Biotechnol. Bioeng. 16, 41-59. doi: 10.1002/bit.260160105

Yan, X., Akiyama, H., Yagi, K., and Akimoto, H. (2009). Global estimations of the inventory and mitigation potential of methane emissions from rice cultivation conducted using the 2006 Intergovernmental Panel on Climate Change Guidelines. Glob. Biogeochem. Cycles 23, 1-15. doi: 10.1029/2008gb00 3299

Ye, R. W., Yao, H., Stead, K., Wang, T., Tao, L., Cheng, Q., et al. (2007). Construction of the astaxanthin biosynthetic pathway in a methanotrophic bacterium Methylomonas sp. strain 16a. J. Indust. Microbiol. Biotechnol. Bioeng. 34:289. doi: 10.1007/s10295-006-0197-x

Conflict of Interest: The authors declare that the research was conducted in the absence of any commercial or financial relationships that could be construed as a potential conflict of interest.

Publisher's Note: All claims expressed in this article are solely those of the authors and do not necessarily represent those of their affiliated organizations, or those of the publisher, the editors and the reviewers. Any product that may be evaluated in this article, or claim that may be made by its manufacturer, is not guaranteed or endorsed by the publisher.

Copyright (c) 2021 Rahalkar, Khatri, Pandit, Bahulikar and Mohite. This is an openaccess article distributed under the terms of the Creative Commons Attribution License (CC BY). The use, distribution or reproduction in other forums is permitted, provided the original author(s) and the copyright owner(s) are credited and that the original publication in this journal is cited, in accordance with accepted academic practice. No use, distribution or reproduction is permitted which does not comply with these terms. 